\title{
EL ARTE DE EDUCAR ${ }^{1}$
}

Pável Florenski, El arte de educar (edición de N. Valentini, trad. de J. R. Pérez Arangüena), Sevilla: Ediciones de la Fundación Altair, 224 pág. 2017.

En este cuidado libro de la Fundación Altair, José Ramón Pérez Arangüena traduce al español la edición de Natalino Valentini de una compilación de textos de Pável Florenski, titulada Florenskij. L'arte di educare, publicada en Brescia, Italia, 2015 por la editorial Morcelliana.

El arte de educar ha llegado a mis manos gracias a la gentileza de Fidel Villegas, director de la colección Studia Humanitatis de las Ediciones de la Fundación Altair. Esta cadena de personas involucradas en la laboriosa y esmerada transmisión del pensamiento de Pável Florenski, de la que hemos mencionado solamente los últimos eslabones, conforma un verdadero testimonio del irresistible poder de irradiación y atracción que ejerce en sus lectores el genial polifacético pensador ruso.

Personalmente tuve el don de entrar en contacto con su mundo espiritual por primera vez gracias a unas notas a pie de página del libro de Alfredo Sáenz, El icono. Esplendor de lo sagrado (Buenos Aires, Gladius, 1977). Y me ha ocurrido, como a tantos otros, que a partir de ese primer contacto fui tirando del hilo de su obra y aún hoy más de veinte años después, Pável Florenski sigue siendo una cantera inagotable de revelaciones que acompañan y transforman mi vida.

El arte de educar acerca a los lectores de habla española un verdadero florilegio de pensamientos que echan luz a cuestiones esenciales de la existencia humana. Y si la educación consiste en asistir a engendrar la riqueza de posibilidades contenidas en nuestra naturaleza el nombre del libro acierta con el meollo de la cuestión.

"Educar en el misterio de la vida, Formas de la paideía en Pável Florenski." Es el título del completo estudio introductorio de Natalino Valentini. Aborda allí la vida, el itinerario intelectual, espiritual y las vicisitudes personales del Padre Pável, poniendo magistralmente en contexto la ocasión de elaboración de los párrafos escogidos para la edición.

La mirada de la infancia, su natural apertura al misterio, la gravitación hacia las capas más densas y profundas de la experiencia, la valoración y el

${ }^{1}$ DOI: https://doi.org/10.46553/sty.30.30.2021.p273-274

Stylos. 2021; 30 (30); pp. 273-274; ISSN: 0327-8859; E-ISSN: 2683-7900 
respeto por el legado de la cultura, la necesidad de desarrollarse a partir de la memoria, desde el reconocimiento de la belleza como realización del amor y su hogar propio, cálido, seguro: la amistad, puente entre el cielo y la tierra. Cada uno de estos temas es ilustrado, desbordado, (fons vincit sitientem) por los textos escogidos del libro que pertenecen principalmente a las Cartas de la prisión y de los campos y a las Memorias de días pasados, entre otras obras, varias de las cuales aún no han sido publicadas en español.

Figura también en el libro un extenso listado bibliográfico de los escritos de Pável Florenski traducidos al español y al italiano, así como de estudios sobre su pensamiento en ambos idiomas.

Esta esmerada edición de la Fundación Altair es una excelente introducción a Florenski. El lector encontrará allí una selección de joyas singulares, ventanas a la realidad que han sido abiertas de par en par por un auténtico titán de la existencia humana. Pero esto sólo a condición de que el lector siga también él, el consejo dado por Floresnki a su querida hija Olga: "cuando más lentamente leas, mejor", "hay que luchar contra la avidez y el deseo de crecer forzadamente, en contra de las leyes internas del crecimiento. Todo llegará a su tiempo y todo se completará si va madurando poco a poco y serenamente. [...] Deja que los conceptos se formen gradualmente en ti: solo en esas condiciones los cristales se forman transparentes [...] ESPERA QUE LOS CONOCIMIENTOS CREZCAN POR SÍ SOLOS, ORGÁNICAMENTE.” (p. 140). Así escrito. Con mayúsculas. Invitándonos desde el abismo del gulag a prestar especial atención sobre la vital importancia de detenernos reverencialmente ante las puertas de la celosa Sophía y permitirle que haga su trabajo en nosotros.

Marisa Mosto

UCA 